\title{
Morfologia e geomorfologia urbana: sistemas territoriais e as margens fluviais em Parintins (AM)
}

\author{
The urban's morphology and geomorphology: \\ territory systems and river edge in Parintins (AM) \\ Estevan BARTOLI ${ }^{\mathrm{A}}$ \\ Rildo Oliveira Marques ${ }^{B}$ \\ ${ }^{a}$ Professor da Universidade do Estado do Amazonas (UEA). \\ E-mail: ebartoli11@gmail.com \\ ${ }^{\text {b }}$ Professor da Secretaria de Educação do Estado do Amazonas. \\ E-mail: rildomarques.geo@gmail.com
}

\begin{abstract}
O objetivo do artigo é demonstrar que a análise do sítio urbano, da expansão do plano e a influência dos sistemas territoriais devem ser feitos em conjunto para o entendimento da configuração da morfologia urbana de Parintins (AM). Descreve-se, inicialmente, o histórico da ocupação do arquipélago fluvial, os eventos e processos socioespaciais associados e os papéis exercidos na rede urbana em ciclos e fases político-econômicas. Maior atenção é dada aos setores econômicos dominantes na cidade cujas práticas espaciais alteram padrões de configuração urbana pela privatização das margens fluviais mais bem localizadas, limitando o uso por setores populares. Sobre o fenômeno das "terras caídas" (erosão das margens fluviais), apresentam-se levantamentos batimétricos e análise de perfis transversais do leito que explicam a constante perda de terras do sítio urbano ao longo da margem do rio Amazonas. Com isso, constata-se que o problema tem intensificado a disputa de agentes dominantes pela posse de lotes aptos para uso portuário. Conclui-se apresentando uma proposta metodológica para estudos de cidades com dinâmicas ribeirinhas e fluviais, considerando sistemas territoriais compostos por redes de sujeitos locais relacionados aos aspectos geomorfológicos.
\end{abstract}

Palavras-chave: cidade, sítio urbano, expansão do plano, redes de sujeitos, terras caídas.

This article aims to demonstrate that urban site, planning expansion, and territorial systems influence should be analyzed in combination to understand the configuration of the urban morphology of Parintins (AM). Initially, it describes the occupation history of the fluvial archipelago, associated socio-spatial events and processes, and roles played in cycles and political-economic phases in the urban network. This study is primarily focused on the dominant economic sectors in the city, whose spatial practices of privatizing better-located riverbanks alter urban configuration patterns, limiting use by popular sectors. Regarding the "fallen lands" phenomenon (fluvial erosion), the article presents bathymetric surveys and transverse profiles analysis of the Amazon riverbed, explaining the constant land loss in the urban site along the its riverbank. The results indicate that this problem has intensified the dispute of dominant agents for lots suitable to be used as ports. Finally, this study proposes a methodology for studies on cities with riverine and fluvial dynamics, considering territorial systems composed by networks of local subjects related to geomorphological aspects.

Keywords: city, urban site, plan expansion, subject networks, fallen lands. 


\section{INTRODUÇÃO}

Este texto pretende aprofunda o diálogo entre dois campos de análise presentes na ciência geográfica, os estudos urbanos e a geomorfologia. O primeiro campo, mais precisamente, trata-se de dinâmicas da produção do espaço intraurbano de Parintins (AM), cidade com características peculiares quanto ao sítio (arquipélago fluvial), com situação na rede urbana dinamizada por transportes fluviais. Da geomorfologia, as contribuições ocorrem na análise das condicionantes físicas do sítio, delimitando ocupações urbanas. O objetivo do artigo é analisar a expansão do plano urbano levando em consideração aspectos do sítio urbano e da influência dos sistemas territoriais, feitos em conjunto para o entendimento da configuração da morfologia urbana de Parintins (AM). Mais precisamente, objetiva aprofundar a análise sobre os fragmentos mais importantes de cidades com dinâmicas ribeirinhas e intenso transporte fluvial: as margens fluviais, cujo problema da erosão ("terras caídas") causou perda de áreas frontais da sede municipal de Parintins (MARQUES, 2017), tornando ainda mais raras margens aptas a uso de portos que se tornam objetos de disputas por redes de sujeitos locais (BARTOLI, 2017, 2018b).

No primeiro momento do texto, demonstra-se a periodização do espaço intraurbano de Parintins, com análise de sua transformação junto às variações abruptas dos ciclos econômicos, associando com a descrição das características físicas do sítio. Constata-se que elites locais alteram suas estratégias e usam o espaço urbano com locus privilegiado de ações, modelando o mesmo para reprodução de práticas espaciais.

No segundo momento, descreve-se a expansão urbana nas décadas de 1990 a 2010: formação de ocupações irregulares populares e loteamentos regulares recentes. Constam-se os limites do sítio salientando papéis de redes de sujeitos locais na configuração da ocupação da terra urbana.

No terceiro subitem, detalham-se aspectos geomorfológicos que formam o arquipélago urbano e os problemas oriundos da erosão de margens fluviais, tendo como base a metodologia empregada em Marques (2017), apresentando uso de levantamentos batimétricos e análise de perfis transversais do leito do rio Amazonas. Constata-se que o problema tem intensificado a disputa de agentes dominantes pela posse de lotes frontais à margem fluvial não sujeita ao fenômeno e aptas para uso portuário.

Finalizando, maior atenção é dada aos setores econômicos dominantes da cidade, cujas práticas espaciais alteram padrões de configuração urbana pela privatização das margens fluviais Amazonas. Os setores populares que utilizam intensamente transportes fluviais são impactados nessa disputa. Nesse tipo de estudo sobre morfologia urbana, dialoga-se com a proposta de entendimento dessas relações de poder que conforma Sistemas Territoriais (BARTOLI, 2017, 2018a, 2018b), cuja análise constata que, além das disputas por terrenos com melhores condições para atracagem de balsas e embarcações de ferro, é necessário entendimento de aspectos da sazonalidade hídrica e das funções que a cidade cumpre na rede urbana a partir de sistemas territoriais.

Uma proposta metodológica que auxilie esses estudos das formas (sítio) e processos (aspectos situacionais) é apresentada no último item, visando a aplicação desse modelo de estudo em cidades com características semelhantes.

\section{Períodos ECONÔMICOS E ESPAÇO IN- traurbano EM Parintins}

Situada a extremo leste do estado do Amazonas (Figura 1), o município encontra-se na divisa com o Pará, limítrofe ao município de Juruti (PA). A sede municipal situa-se na margem direita da calha do rio Amazonas, com navegação sem restrições durante todo o ano (mesmo em anos de secas severas), que posiciona a cidade em ponto estratégico entre as duas metrópoles regionais, Manaus (AM) e Belém (PA). Outras conexões para comunidades e pequenos municípios ao norte e sul da sede municipal são mais afetadas no período de secas, alterando rotas de navegação que se tornam mais longas. As ligações com a rede urbana são primordialmente fluviais, o que confere maior peso ao papel das embarcações e redes de sujeitos locais que estão vinculadas. Grupos comerciais que possuem glebas na margem fluvial frontal se beneficiam por obter os melhores portos da cidade.

Os materiais e métodos das reflexões e resultados apresentados neste e nos próximos subtítulos foram feitos a partir de revisão bibliográfica e de diversas pesquisas realizadas no Núcleo de Estudos Territoriais da Amazônia (Netam) ${ }^{1}$.

1 Sediado na Universidade do Estado do Amazonas, campus de Parintins. 
Figura 1. Localização da sede de Parintins (AM).
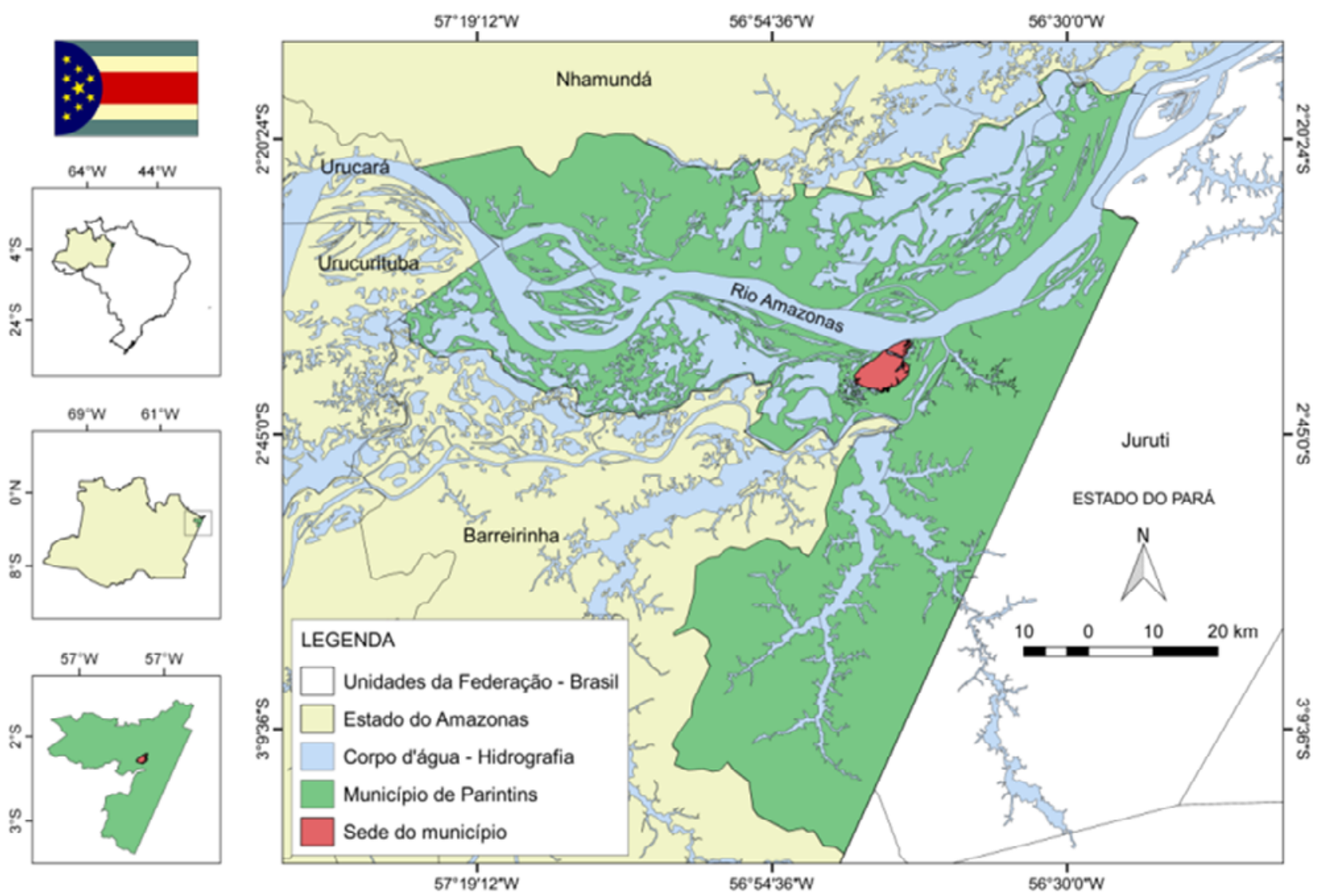

Fonte: Base cartográfica do Instituto Brasileiro de Geografia e Estatística (IBGE), 2010. Organizada por Marques (2017).

Desde os estudos clássicos sobre periodização da rede de cidades na Amazônia brasileira de Corrêa (2006), cuja importância reside em averiguar as funções dos centros urbanos nas sucessivas fases econômicas regionais, surge a necessidade do entendimento da articulação entre as dimensões intra e interurbana (SPOSITO, 2007). Na constante marcha de integração regional amazônica ao restante do país, as cidades passam a cumprir diferentes papéis relativos às frações diversas de reprodução do capital, desde as incursões de maior intensidade no período militar até as redefinições e embates de forças atuais, como, por exemplo, o avanço do agronegócio e a resistência de populações tradicionais (BECKER, 2005).

Portanto diversas realidades atreladas às produções espaciais dos espaços sub-regionais e urbanos foram se configurando, num mosaico de cidades vinculadas às mais variadas frentes de expansão das atividades capitalistas, resultando no que Trindade Júnior (2010) chamou de "urbanodiversidade". Essas frentes mais recentes de desenvolvimento urbano se sobrepõem a uma rede urbana já existente, redinamizando alguns pontos do território e enfraquecendo outros.

Das elites formadas em diferentes fases, do período áureo da borracha aos ciclos extrativos subsequentes à produção da juta, busca-se entender como a fração mercantil ainda predominante em Parintins veio configurando seu espaço intraurbano.

Para Corrêa (2006), a periodização espacial reconstrói o tempo espacial, ou seja, coloca em evidência momentos diferenciados que caracterizam o processo de elaboração da organização espacial. Demonstram-se, de maneira sucinta, os principais eventos na periodização da rede urbana e a inserção de Parintins nas diversas fases de desenvolvimento econômico, enfocando alterações das formas na expansão urbana, impactos e consequências. Desde a ocupação do Vale Amazônico, a partir do século XVII, com a chegada da coroa portuguesa, sequenciais ciclos econômicos foram configurando a rede urbana embrionária e dendrítica com a construção de fortes e a intensificação da busca por "drogas do sertão" a partir de 1655 (CORRÊA, 2006, p. 72). Os sucessivos ciclos 
econômicos a partir da implantação da Companhia Geral do Grão-Pará e Maranhão (1755) e as políticas do Marquês de Pombal (até 1780) aprofundaram o desenvolvimento da rede e alteraram os rumos da região, com diversas políticas impondo restrições ao poder eclesiástico, doando sesmarias a colonos e soldados, expandindo cultivos e extrativismo, com criação de numerosos Fortes e, principalmente, elevando 46 Aldeias missionárias à categoria de vilas, entre elas a Vila Bela da Imperatriz, futura Parintins (BITTENCOURT, 1924).

O período da borracha (1850 a 1920) impactou muito pouco a sub-região de Parintins e sua rede urbana, devido aos parcos investimentos propiciados pela economia gomífera (SAUNIER, 2003). Estruturou timidamente a configuração inicial do plano urbano, com a cidade apresentando relativo crescimento populacional, e definiu a futura expansão e consolidação do centro comercial e administrativo. Nesse período, a Vila Bela da Imperatriz é elevada à categoria de cidade em 1880, nomeando-se Parintins em homenagem aos precedentes habitantes indígenas, os Parintintins, que foram dizimados, fugiram ou foram aculturados (SAUNIER, 2013).

A partir de 1933, entre o trecho de Manaus e Santarém, teve início a implantação do ciclo da juta partindo de Parintins, que foi polo propulsor das experimentações no plantio da fibra vegetal destinada à produção de sacarias para exportação do café brasileiro. O Governo Federal, em 1930, concede permissão para órgãos japoneses fundarem em Parintins o Instituto de Estudos Agrícolas para imigração japonesa, na Vila Amazônia, próxima ao núcleo central (ROSAL, 2000).

Como salienta Marques (2017), a partir da década de 1950, a erosão de margens fluviais já consta como problema eminente e já presente na agenda de discussões da política local, tema aprofundado no terceiro subitem deste trabalho.

A partir de 1970, o espaço intraurbano começa a ser alterado com maior intensidade, principalmente pela atividade da juticultura na implantação de fixos (galpões e fábricas), surgimento de novos bairros e instalação de universidades cuja função de polo se aprofunda posteriormente (BARTOLI, 2017). A partir da década de 1970, o fator sítio urbano veio sendo primordial no entendimento da dinâmica do crescimento urbano, ocorrendo a primeira expansão urbana abrupta nessa década. Em 1975, uma das maiores enchentes registradas no estado veio impactar a estruturação da cidade, causando grande migração de ribeirinhos para a área urbana, registrando a primeira explosão demográfica de
Parintins. Este fenômeno determinou a ação do poder público para criação dos bairros da Francesa e Santa Clara e formação dos bairros de Palmares, Santa Rita de Cássia, Nazaré e São Vicente de Paula, processo que se intensificou na ocupação da área urbana (CARVALHO, 2013; SOUZA, 2013).

As margens fluviais e dos lagos no interior do arquipélago urbano passaram a ser ocupadas a partir da década de 1980. Parte desses terrenos se encontra em ambientes rebaixados e são anualmente colmatados e inundados em grandes cheias, sobretudo as áreas de transição entre ilhas, que nas últimas décadas passaram a formar grandes aglomerações palafíticas. Em Parintins, o rio Amazonas tem início de período de cheia em novembro/dezembro e vai até junho/julho. Já a vazante começa em julho/agosto e se estende até outubro/ novembro. Verifica-se que o rio leva de sete a oito meses até atingir a cota máxima e desce em apenas quatro a cinco meses (MARQUES, 2017).

O comportamento hidrológico dos últimos 30 anos do rio Amazonas em Parintins projeta uma tendência ao aumento de grandes enchentes, ou seja, com nível acima da cota dos nove metros, característica observada nas duas últimas décadas no médio e baixo Amazonas (MARQUES, 2017). Os dados da Agência Nacional de Águas (2015) mostram ainda ligeiro aumento relacionado à ocorrência de vazantes. Nos anos de 1997, 2005 e 2010, foram registradas as maiores vazantes (popularmente chamadas de secas) dos últimos 30 anos, causando impactos não somente em Parintins, mas em vários municípios do estado do Amazonas, dificultando a navegabilidade e deixando várias comunidades e vilas isoladas.

Desde 1990, Parintins vem se consolidando como cidade média de responsabilidade territorial, ampliando funções de fornecimento de serviços educacionais, saúde, entre outras funções (SCHOR; OLIVEIRA, 2016). Consolida-se, ainda, como centro sub-regional distribuidor de mercadorias (BARTOLI, 2018a).

Estudos demonstram como o capital mercantil veio se apropriando e se cristalizando no espaço intraurbano de Parintins (CARVALHO, 2013). Mapeamentos de uso da terra urbana (COSTA NETO, 2011) demonstram a apropriação das margens fluviais por empresas comerciais e pequenas indústrias, e, consequentemente, os impactos ambientais gerados por tais atividades portuárias, hoteleiras, madeireiras, olarias etc. As margens fluviais no centro de Parintins e nos bairros valorizados do entorno vêm sendo afetadas por esse processo, com instalação de fixos por setores da economia popular e por grupos 
de empresários locais em intensa disputa por vantagens para atracagem de embarcações. Essas disputas se dão em torno de um sítio que apresenta, há anos, o solapamento das margens fluviais.

Após expansão das décadas de 1990 a 2010, as margens fluviais centrais e demais que acessam o rio Amazonas tiveram ocupação intensificada, assim como outras margens fluviais do arquipélago urbano (BARTOLI, 2018b).

\section{A EXPANSÃO URBANA NAS DÉCADAS DE 1990 E 2010: OCUPAÇÕES IRREGULARES, ESPAÇO PERIURBANO E LOTEAMENTOS RECENTES}

A segunda expansão abrupta do plano urbano de Parintins ocorre nas décadas de 1990 e 2010, incentivada pelos seguintes processos: surgimento de novas formas de moradia "beira-de-rio" (palafitas), formação de loteamentos populares periféricos oriundos de ocupações irregulares, loteamentos periurbanos com forte especulação imobiliária ligada a programas de financiamento federais e criação do primeiro loteamento fechado da cidade (BARTOLI, 2019a).

Nessas décadas ocorreram na cidade alterações profundas na sua configuração espacial devido à formação do chamado ciclo das ocupações irregulares, a partir dos anos 1990 (Figura 2). Trata-se da formação dos quatro bairros mais populosos do município: Itaúna I, Itaúna II, Paulo Corrêa e União que, juntos, abarcam 41.163 habitantes (SEGRETARIA MUNICIPAL DE ASSISTÊNCIA SOCIAL E TRABALHO, 2009). Esse ciclo de ocupações irregulares causou o início da ocupação da segunda ilha principal (Figura 2), que constitui sítio apto à expansão urbana. As áreas ocupadas em 1990 pertenciam ao empresário paraense Paulo Corrêa, que foi indenizado posteriormente pela prefeitura (BARTOLI, 2017). Esse contexto nos remete a evidenciar o peso das populações de baixa renda como agentes produtores do espaço, em que a forte demanda popular e a formação da "cidade ilegal" se associam a disputas de poder e tentativas de regularização dos lotes na formação de bairros como clientelas eleitorais. Trata-se de uma velha prática em novas geografias, que possibilitaram a formação de novos eixos e futuro avanço do plano urbano em expansão rumo à periferia, onde áreas rurais e antigas fazendas posteriormente passaram a se transformar em loteamentos (BARTOLI, 2018b).

Os impactos das ocupações irregulares transformados em bairros na morfologia da cidade foram enormes, pois estiveram atrelados à superação dos limites físicos impostos pelo sítio, sendo necessários vários aterros sobre o lago Macurany e a construção de duas pontes (Figura 2).

O ciclo de sucessivas ocupações pressionaram os proprietários fundiários das áreas periféricas circunvizinhas, donos de antigas fazendas de gado desativadas, que, amedrontados com a rápida expansão do processo, decidiram lotear suas glebas, conforme aponta Nascimento (201 1). Outro dado interessante presente nos relatos dos proprietários ocorre no processo de planejamento urbanístico dos loteamentos, em que os próprios fazendeiros foram responsáveis pelo traçado da malha (largura das ruas, sentido, forma, tamanho dos quarteirões), que estruturam os loteamentos Pascoal Alágio e Jacareacanga, originando dois novos bairros caracterizados como loteamentos regulares aprovados pela prefeitura (NASCIMENTO, 2011).

Fica clara, com a implantação da malha ortogonal dos novos bairros, a falta de critérios da solução urbanística na disposição das ruas e total negação às nuances do relevo e hidrografia e seus usos de margens fluviais por populares. Houve desvalorização do sítio e desconsideração às prementes necessidades de acesso de populações às margens do lago Macurany, que ocorre hoje apenas em pontas de rua, limitando o potencial de uso da lagoa. Essa perda de acesso às margens veio sendo acentuada com os conjuntos de palafitas e posterior substituição em alguns trechos por casarões e sítios pertencentes às elites locais (BARTOLI, 2018b). 
Figura 2. Expansão do plano urbano de Parintins por décadas.

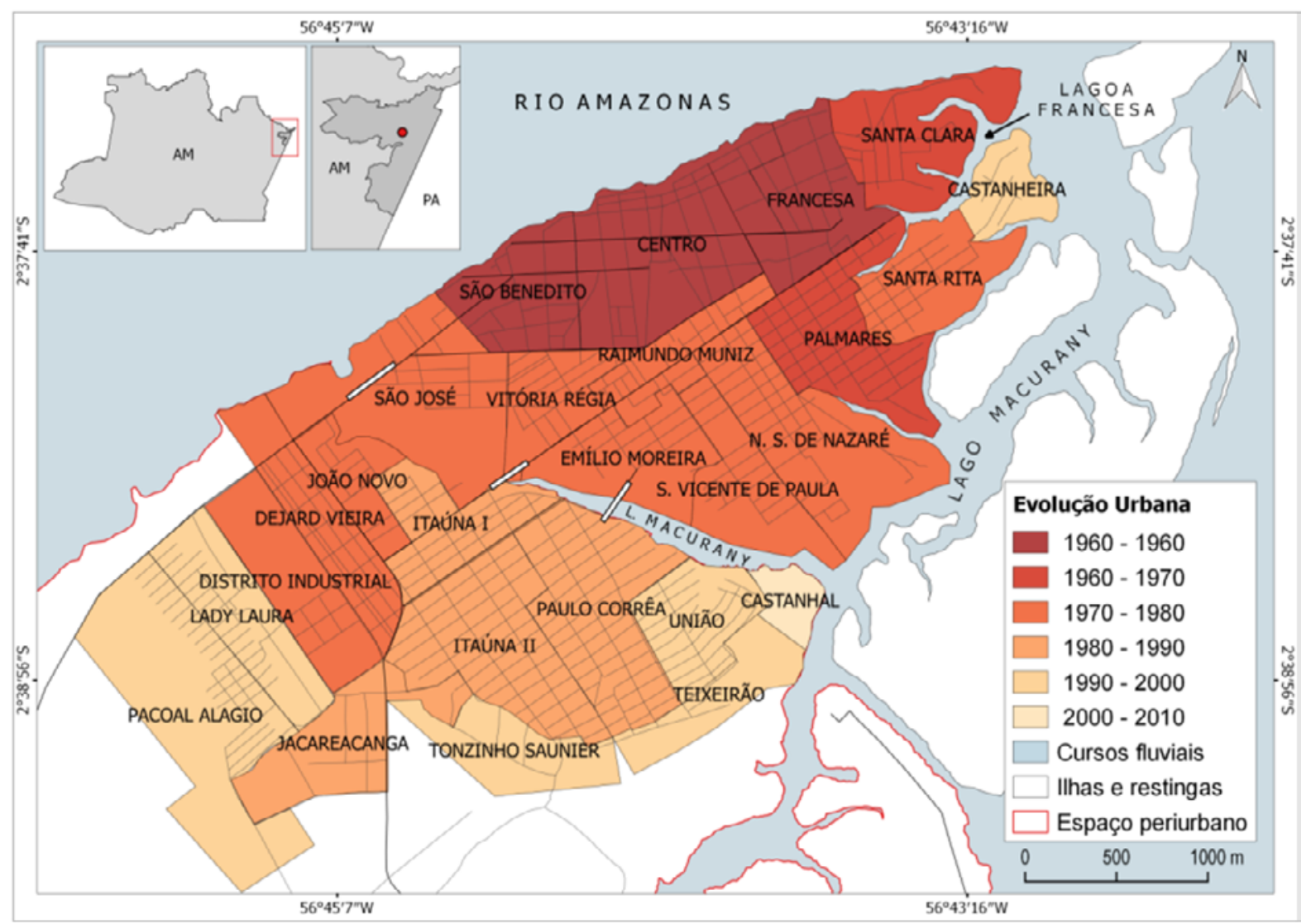

Fonte: Base cartográfica IBGE, 2010. Adaptado de Bartoli (2017).

\section{O ARQUIPÉLAGO URBANO: ASPECTOS GEOMORFOLÓGICOS E EROSÃO DA MARGEM FLUVIAL}

O sítio urbano de Parintins localiza-se em um arquipélago na margem direita do rio Amazonas, com uma base formada por rochas lateríticas que se estendem pela faixa justafluvial do rio Amazonas em subsuperfície. No entorno do arquipélago, podem-se notar ainda planícies inundáveis, baixas e enseadas naturais que condicionam extensas áreas de acesso fluvial ao interior do sítio (MARQUES, 2017).

No contato com o rio Amazonas, o terraço apresenta pontos críticos de erosão de margens fluviais, que afeta e desvaloriza portos, terrenos particulares, vias de acesso, áreas de lazer, além de causar riscos à circulação de veículos e à navegação (MARQUES, 2017).

Levantamentos batimétricos recentes no rio Amazonas feitos por Marques (2017) mostram que o talvegue do rio (ponto de maior profundidade, turbulência e velocidade) acompanha e está em processo de encaixe junto à margem fluvial do arquipélago urbano de Parintins. Isso tem relação direta com os processos erosivos. Essa característica é atribuída à posição da cidade em um ponto de inflexão do canal e a sua influência na distribuição das correntes fluviais.

Os quatro perfis do leito do rio Amazonas descritos a seguir foram elaborados por Marques (2017) e serão relacionados ao uso da terra urbana nas margens fluviais no próximo item, demonstrando a seletividade e disputas entre redes de sujeitos locais.

O primeiro perfil do leito do rio Amazonas, que vai da Praça Comunas (margem direita) para a ilha do Espírito Santo (margem esquerda), no bairro Centro, possui cerca de $3.500 \mathrm{~m}$ de largura e a seção transversal mostra o canal com leito assimétrico e com maior profundidade junto à margem direita (Quadro 1). Nesse ponto, o talvegue atinge $85 \mathrm{~m}$ de profundidade a uma distância de $328 \mathrm{~m}$ da margem, promovendo condições para a ocorrência de erosão das margens fluviais. Mais detalhes das localizações no sítio e plano urbanos serão apresentados na Figura 5.

O segundo perfil (Quadro 1) representa o leito que se estende do Terminal Hidroviário, bairro Centro, 
até à ilha do Espírito Santo. A largura alcançada pelo rio Amazonas neste ponto é de $3.190 \mathrm{~m}$, e o talvegue também se encontra encaixado na margem direita com uma profundidade de $90 \mathrm{~m}$.

No terceiro perfil, é observada a maior assimetria do canal. O talvegue do rio Amazonas torna-se largo e profundo, chegando a atingir $98 \mathrm{~m}$, a uma distância de 473,2 m da margem direita. Próximo à margem esquerda, a seção transversal aponta a existência de um canal mais raso com regularidade de $20 \mathrm{~m}$.

O quarto perfil, que se vai do bairro Santa Clara para a ilha do Espírito Santo, mostra o canal mais estreito $(2.650 \mathrm{~m})$ e a área ocupada pelo talvegue mais extensa, aumentando, consequentemente, áreas de maior velocidade e turbulência. As condições da margem em forma de falésia, sem estrutura de contenção, limitam o uso e a atracagem de embarcações, que se restringem mais ao uso popular, mas que, no período de vazante, é disputada também por balsas de ferro de grupos locais dominantes (capital mercantil e grandes comerciantes).

Os perfis transversais mostram que a corrente principal desloca-se em direção ao arquipélago urbano, pois a forma sinuosa da margem e o estreitamento do canal, que varia de $3.500 \mathrm{~m}$ de largura no limite superior (montante) para apenas $2.650 \mathrm{~m}$ no limite inferior (jusante), contribui para que ocorra maior pressão do volume de água no trecho mais jusante da cidade, que corresponde ao bairro Santa Clara (Quadro 1). A localização de cada um dos perfis é apresentada na Figura 5, adiante.

Quadro 1. Perfis transversais a partir de levantamento batimétrico.

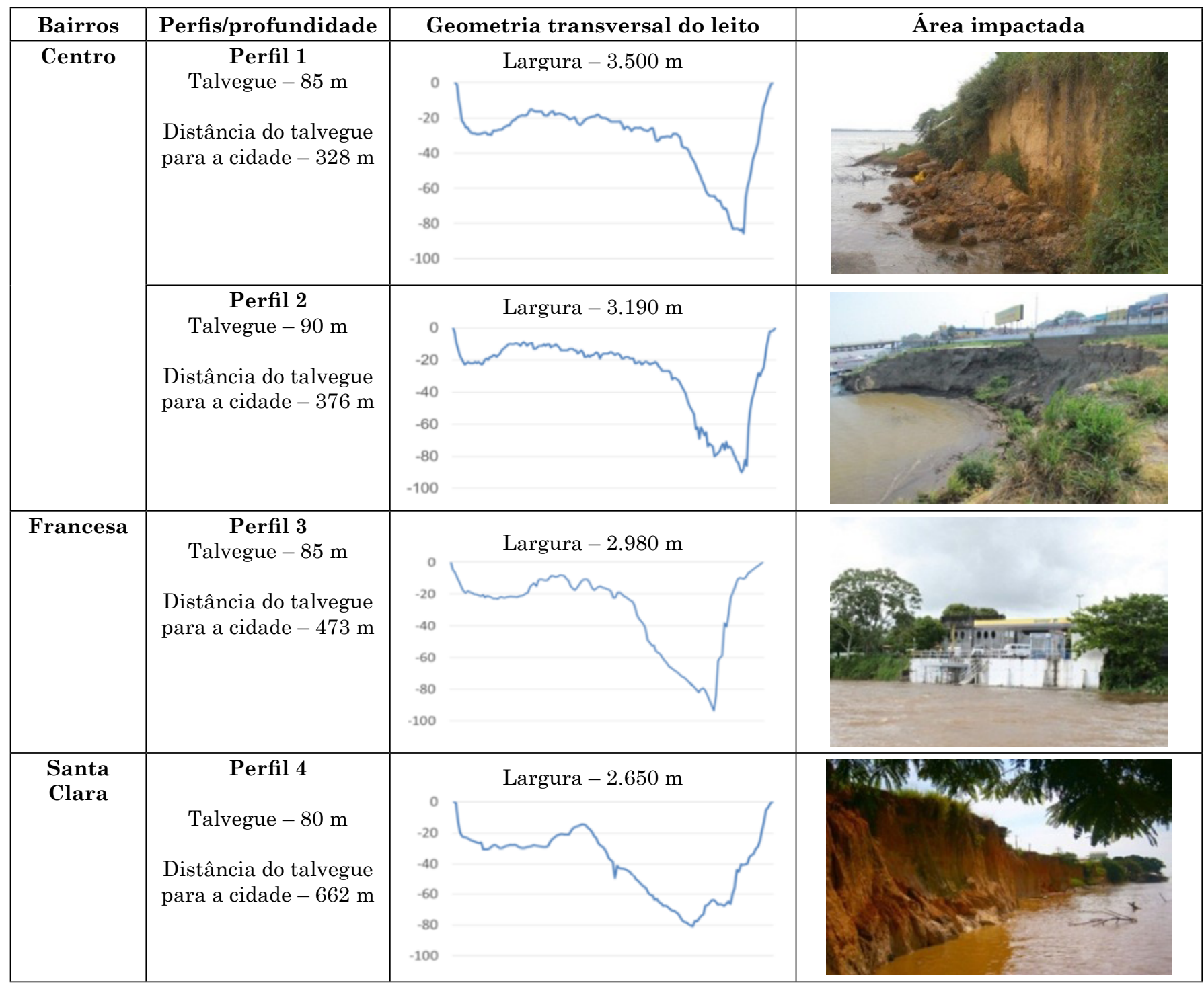

Fonte: Adaptado de Marques (2017). 
Como descrito anteriormente, a evolução do plano urbano de décadas mais recentes entre as ilhas que compõe o sítio é outro aspecto a ser levando em conta. $\mathrm{O}$ aterro da Rodovia ${ }^{2}$ Odovaldo Novo sobre um canal ligando as duas principais ilhas direcionou o impacto hidráulico do rio Amazonas que esse canal recebia para jusante, forçando o contorno fluvial da primeira ilha ocupada a sofrer maior pressão. Em parte, isso explica o aumento recente, nas ultimas décadas, de desabamento de terras na "orla" do arquipélago urbano.

Além da forma e geometria do leito, vários fatores hidráulicos afetam a estabilidade o sítio, no entanto sua maioria depende das propriedades específicas da água que se relacionam com as forças hidráulicas atuantes dentro do canal.

Carvalho (2006) considera que, no rio Amazonas, um dos principais fatores que atuam dentro do canal e que se apontam como os principais responsáveis pelas "terras caídas" é a grande energia contida em seu descomunal volume de água, associado às "macroturbulências" com que os fluxos se deslocam dentro do canal e o peso que esse volume de água exerce dentro dele.

Os dados de medições hidrológicas realizadas logo a jusante da cidade de Parintins pelo Programa Hidrologia e Geoquímica da Bacia Amazônica (Hibam) mostram que, em 12 de dezembro de 2003, quando o rio Amazonas estava em período de vazante, a vazão média foi de $107.393 \mathrm{~m}^{3} / \mathrm{s}$. Em abril de 2005, quando o rio estava enchendo, a expedição encontrou vazão média de $182.180 \mathrm{~m}^{3} / \mathrm{s}$. E, em junho do mesmo ano, quando o rio atingiu a cota máxima de cheia, a vazão média foi de $192.262 \mathrm{~m}^{3} / \mathrm{s}$. Ou seja, o volume de água que passa na frente da cidade varia de 107.000 a $190.000 \mathrm{~m}^{3} / \mathrm{s}$. É o ataque desse descomunal volume de água, associado com a forma turbulenta com que se desloca dentro do canal e atinge a margem, que atua como o principal responsável pelo solapamento da base dos taludes fluviais, comprometendo o acesso frontal da cidade a partir do rio Amazonas (MARQUES, 2017).

A atuação dos fatores climáticos na erosão das margens é amplamente observada e considerada no conjunto de mecanismos. No rio Amazonas, Carvalho (2006) aponta que as chuvas e, sobretudo, os ventos estão entre os fatores que contribuem mais diretamente com esse processo.

2 O termo "rodovia" aparece nos registros oficiais da prefeitura, mas esta não conecta o plano urbano a outras localidades, apenas realizando ligação com áreas periurbanas.
O rio Amazonas, no trecho que margeia a cidade de Parintins, apresenta condições favoráveis à ação e a formação de corredores de vento que atuam na formação de ondas, pois possui uma calha larga e pouco sinuosa, variável entre $3.500 \mathrm{~m}$ de largura no limite superior e $2.650 \mathrm{~m}$ no limite inferior, e com profundidade máxima que chega a uma média de $87 \mathrm{~m}$.

Por fim, considera-se que a erosão de margens fluviais no arquipélago urbano de Parintins recebe influência de ações humanas, como a retirada de rochas lateríticas da base da margem (para uso na construção civil), que atuam como proteção natural, e a canalização do esgoto doméstico e pluvial para a zona de erosão do rio. Outro fator é a formação de ondas geradas pelo constante deslocamento de embarcações regionais. Navios cargueiros também têm contribuído com o processo. Carvalho (2006 p. 84) aponta que "o aumento no trânsito dessas grandes embarcações foi intensificado no rio Amazonas a partir da década de 1970, em função do desenvolvimento da Zona Franca de Manaus". Como Parintins encontra-se à jusante de Manaus, as grandes embarcações de carga vindas a partir do Atlântico para a capital do estado precisam passar em frente à cidade e embora na maioria das vezes reduzam sua velocidade, a onda formada ainda chega a deslocar um grande volume de água contra as margens do sítio, intensificando os processos erosivos.

\section{Morfologia URbana E SISTEMAS TERRITORIAIS}

A análise empreendida pela morfologia urbana supõe sempre atenção aos elementos básicos que configuram o tecido urbano e aos mecanismos de transformação de suas estruturas. Exige sempre uma aproximação estrutural que leve em conta os diversos elementos componentes e suas inter-relações e diacrônica, histórica, que dê conta dessas transformações (CAPEL, 2002). Permite entender a maneira com que o processo de urbanização, em determinados contextos na Amazônia, vem ocorrendo e incita a compreensão das relações entre formas, funções, processos e estruturas, sendo a morfologia uma síntese entre esses elementos.

Portanto, ao partir das formas, pesquisas de Bartoli (2017, 2018b, 2019a, 2019b) indicam que estas denotam certo grau de condicionamento sobre as práticas socioespaciais, enfatizando os principais sistemas territoriais atuantes no espaço urbano. Em uma cidade com forte 
dinâmica ribeirinha, constata-se a existência de centralidades sazonais e fragmentos no espaço intraurbano conectados a pontos do território do entorno. Margens fluviais em bairros populares ou portos privatizados por empresas comerciais da cidade denotam diferentes temporalidades, lógicas de uso e circulação de pessoas.

Como proposta metodológica, apresenta-se um quadro referencial (Quadro 2) para estudos de morfologia urbana em cidades de dinâmica ribeirinha, realizando diálogo entre os trabalhos de Bartoli (2017), sobre redes de sujeitos locais, e Marques (2017), sobre a ocorrência das "terras caídas", onde as margens fluviais são interpretadas como fragmentos do espaço intraurbano, indicando aspectos de como a cidade está inserida na atual divisão social e territorial do trabalho.

Proposta para entendimento de tais dinâmicas ocorre na tese relativa à existência do Sistema Territorial Urbano-Ribeirinho - Stur (BARTOLI, 2017), que trata de um sistema mediador na produção de territorialidades a partir de setores da economia popular. O Stur é dinamizado pela constante circulação de embarcações de setores da economia popular na cidade ou interiores que estão em constante circulação. Realizam atividades econômicas entre a cidade e áreas de entorno como complemento para a combalida economia urbana. Portanto o Stur abastece a economia popular dos bairros periféricos e as empresas pertencentes ao capital mercantil (economia dual), possibilitando extração sazonal de recursos por meio de diversas redes de sujeitos: pescadores, extrativistas, madeireiros, carpinteiros navais, indígenas etc.

O Stur é também utilizado pelos setores mercantis dominantes para distribuição de produtos que chegam de Manaus ou da rede urbana paraense por balsas e grandes navios de ferro. A partir do transporte fluvial em barcos regionais de madeira, desenha outros tipos de "hinterlândias", requerendo metodologia específica, como aponta Bartoli (2017, 2018a), para reconhecimento dos fluxos.

Se há aumento na demanda da cidade para extração de recursos naturais e para distribuir produtos pelas empresas da cidade para cidades menores vizinhas, a demanda por pessoas dispostas a navegar, praticar extrativismo ou realizar cultivos agrícolas diversos também cresce. Isso intensifica a necessidade da mediação entre território-cidade-mercado dinamizada pela circulação fluvial, características centrais do Stur. Os ciclos passados em Parintins da extração do óleo de pau-rosa (seiva para perfumes), cultivo de juta e malva (fibras) na atual extração madeireira ou na pesca são bons exemplos. Tais conhecimentos (saber navegar, transitar e explorar o território num sentido zonal/areal) passam a ser apropriados a serviço de setores mercantis da cidade, direta ou indiretamente. Os impactos desses setores populares na morfologia urbana são apresentados em Bartoli (2017, 2018b) reconfigurando o espaço intraurbano.

Neste item, maior atenção é dada aos setores econômicos dominantes na cidade cujas práticas espaciais alteram padrões de configuração urbana pela privatização das margens fluviais mais bem localizadas. Dois modos de produção do espaço em margens fluviais se desenham pela ação destes setores. O primeiro refere-se à produção de moradias elitizadas, sendo apreensíveis por meio das movimentações intraurbanas de grupos sociais dominantes com algumas semelhanças as metrópoles (BARTOLI, 2017; 2018b). Indicam movimento de classes médias e altas, para novos eixos e áreas de valorização de moradias em direção a periferias com margens fluviais, almejando adicionar elementos ambientais que atribuam status por seu acesso diferencial e apropriação desigual. Os determinantes dessa paulatina substituição de moradias ribeirinhas por casas elitizadas estão relacionados a dois elementos: 1) estruturais: conectividade ao centro, presença de antigos lotes de sítios como reserva de valor e especulação, presença de infraestrutura; 2) conjunturais: valorização de novas formas de moradias causando pressão imobiliária aos imóveis de baixo padrão, valorização do acesso ao rio (para uso náutico ou estético/símbolo de status) e, no caso de Parintins, especulação para aluguéis para o festival folclórico ${ }^{3}$.

O segundo tipo de ocupações nas margens fluviais pelo Sistema Territorial dominante ocorre com a construção de portos, galpões, fábricas de gelo e frigoríficos processadores de peixe, madeireiras, olarias, hotéis entre outras atividades pertencentes aos setores do capital mercantil na cidade (Figura 3). Perceptível na composição da paisagem em Parintins, o capital mercantil veio, ao longo das últimas décadas, se metamorfoseando e se cristalizando no espaço intraurbano, locus privilegiado de suas atividades, que se torna nó multireticular propiciando continuidade de diversas atividades mercantis. Realiza distribuição de produtos industrializados para

3 Durante o festival folclórico de Parintins, várias empresas prestadoras de serviços ao festival ou empresas do Polo Industrial de Manaus alugam casas e sítios. Os locais mais valorizados são os de acesso ao lago Macurany, gerando pressão crescente sobre o preço dos imóveis e, consequentemente, incentivando a saída de moradores em situações mais frágeis, fato em evidencia no local. 
interiores (alimentos, estivas, combustíveis etc.) e absorção de produtos regionais, agrícolas ou da pecuária local. Adota práticas modernas de gestão e passa a ser influenciado pelo capital industrial moderno a quem presta a função de distribuição sub-regional de produtos por meio das empresas comerciais locais. Portanto a apropriação das margens fluviais frontais mais valorizadas da cidade demonstra a função de Parintins enquanto nódulo logístico sub-regional pela presença dos tipos de transporte e empresas comerciais médias, atendendo as cidades circunvizinhas.

Para Cano (2011), há uma metamorfose do capital mercantil antigo nas cidades para novas roupagens. São novas redes atacadistas, hotéis e supermercados, geralmente ocupados pelos descendentes de famílias tradicionais da região. São formas de capital que, muitas vezes, se transformam em capital industrial e bancários ou de financiamento. Mas sempre garantem sua participação no poder local de forma reacionária.

Sua presença no meio rural é conhecida pelas grandes fazendas. Mesmo assim, possuem sede privilegiada no meio urbano para organizar outras atividades, como especulação fundiária e imobiliária, sempre investindo em novas frentes de acumulação ${ }^{4}$. No contexto de Parintins, tal setor se beneficia de exploração de recursos regionais e conta com o trabalho disponível tanto nos interiores quanto na cidade.
4 Em Parintins, os maiores produtores de gado são, hoje, os que mais investem no setor imobiliário local. O primeiro edifício residencial da cidade tem como proprietário um dos grandes fazendeiros. Um dos pecuaristas e dono de loja de materiais de construção entrevistados (BARTOLI, 2019) afirmou que o lucro do gado é cada vez menor e que, hoje, prefere investir no setor imobiliário. Casas em diversos bairros da cidade são construídas e vendidas com auxílio de financiamentos de programas federais.
Figura 3 - Portos do Sistema Territorial UrbanoFluvial e fixos referenciais do capital mercantil.

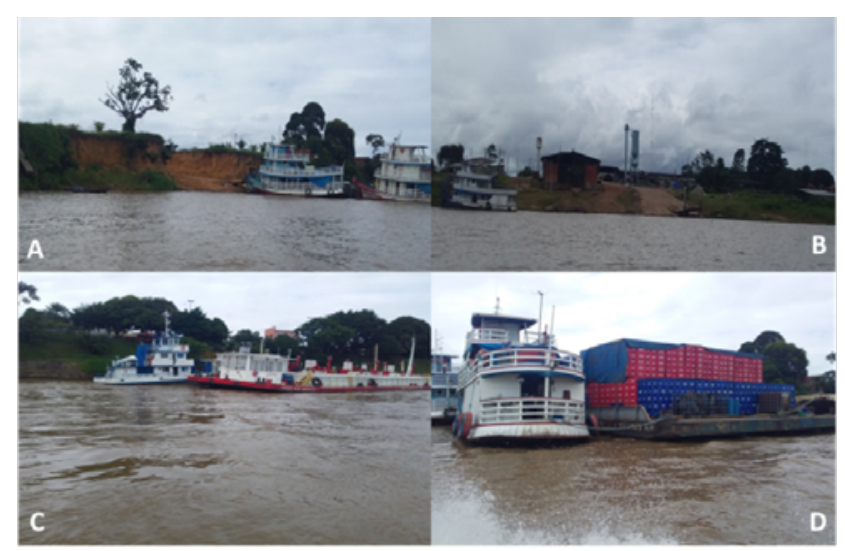

Fonte: trabalho de campo (25/05/2018).

Estudos de caso sobre Parintins revelaram regularidade espacial dos fluxos devido à influência desse sistema mercantil dominante compondo o que Bartoli (2017, 2018a) denominou como Sistema Territorial UrbanoFluvial (Stuf), evidenciado pelo mapeamento de usos do solo urbano nas margens fluviais. $\mathrm{O}$ autor usa o termo urbano-fluvial considerando que, para os sujeitos que animam esse sistema, os rios são usados primordialmente para circulação de mercadorias. A partir da lógica preconizada por esse sistema, não há intenção de manter práticas diárias de populações que têm no rio um aspecto simbólico, cultural/identitário (ribeirinho), lúdico ou para subsistência (BARTOLI, 2017, 2018a). Têm menor vínculo com a cultura local e desconsideração com a manutenção de valores de uso social ${ }^{5}$, gerando conflitos, pois não há permissão para embarcações menores atracar em portos particulares pertencentes ao Stuf. Não têm características de territorialidades vinculadas às dos setores populares nas "beiras de rios" (pesca, ludicidade, moradia). É um sistema vinculado a atividades presentes na cidade ligadas ao capital mercantil, com conexões e relações escalares diversas, principalmente com a metrópole Manaus, por meio de balsas e navios de ferro.

Grupos de empresários locais possuem maior poder de organizar espaços partindo da posse de lotes e

5 Um fato marcante chamou a atenção em 2011. Um cargueiro em direção a Manaus ultrapassou a velocidade permitida de navegação frontal a cidades, causando ondas (chamadas popularmente de banzeiros) que se propagaram e atingiram barcos pequenos e médios ancorados em Parintins. Um exemplo claro de conflito de espaços de uso e fluxos com destinos e sujeitos diferentes. 
glebas que os confere renda diferencial, materializados principalmente nos portos e galpões em localidades estratégicas. As embarcações usadas são grandes balsas de carga, balsas de combustíveis, empurradores, barcos tanque de gasolina, barcos grandes de ferro, lanchas e iates de veraneio ${ }^{6}$.

Devido à ocorrência de processos erosivos nas margens do rio Amazonas, as disputas por terrenos com melhores condições para atracagem de balsas e embarcações de ferro têm conferido vantagens aos grupos dominantes do Stuf. O Sistema Territorial Urbano-Fluvial costuma contar com apoio de prefeitos consolidando setores dominantes nas cidades, modelando a paisagem. No tocante às empresas que compõem o Stuf, sete grupos se destacam pela quantidade de imóveis, portos, galpões, lojas e postos de combustíveis (SILVA, 2018).
No pico da vazante, o rebaixamento do nível das águas inutilizam os principais portos populares. Cursos fluviais como a lagoa da Francesa e lago Macurany têm seu acesso restringido (Figura 1), tornando a margem fluvial com acesso ao rio Amazonas objeto de disputa por espaço e conflitos pelo aumento do número de embarcações populares. As pequenas e médias embarcações se deslocam para áreas frontais que, mesmo desvalorizadas pela erosão de margem fluvial, como no caso do bairro Santa Clara, disputam espaços com embarcações de ferro, como balsas de carga, configurando as chamadas "beiras mistas sazonais".

Nesse sentido, a paisagem da cidade nos indica estruturas que compõem sua morfologia, arranjos organizados de volumes e subparcelamentos (quarteirões, glebas e lotes) que expressam formas de acesso e propriedade, situados em determinado porte físico (LANDIM, 2004).

Figura 4 - Uso da terra urbana e erosão na margem fluvial do rio Amazonas.

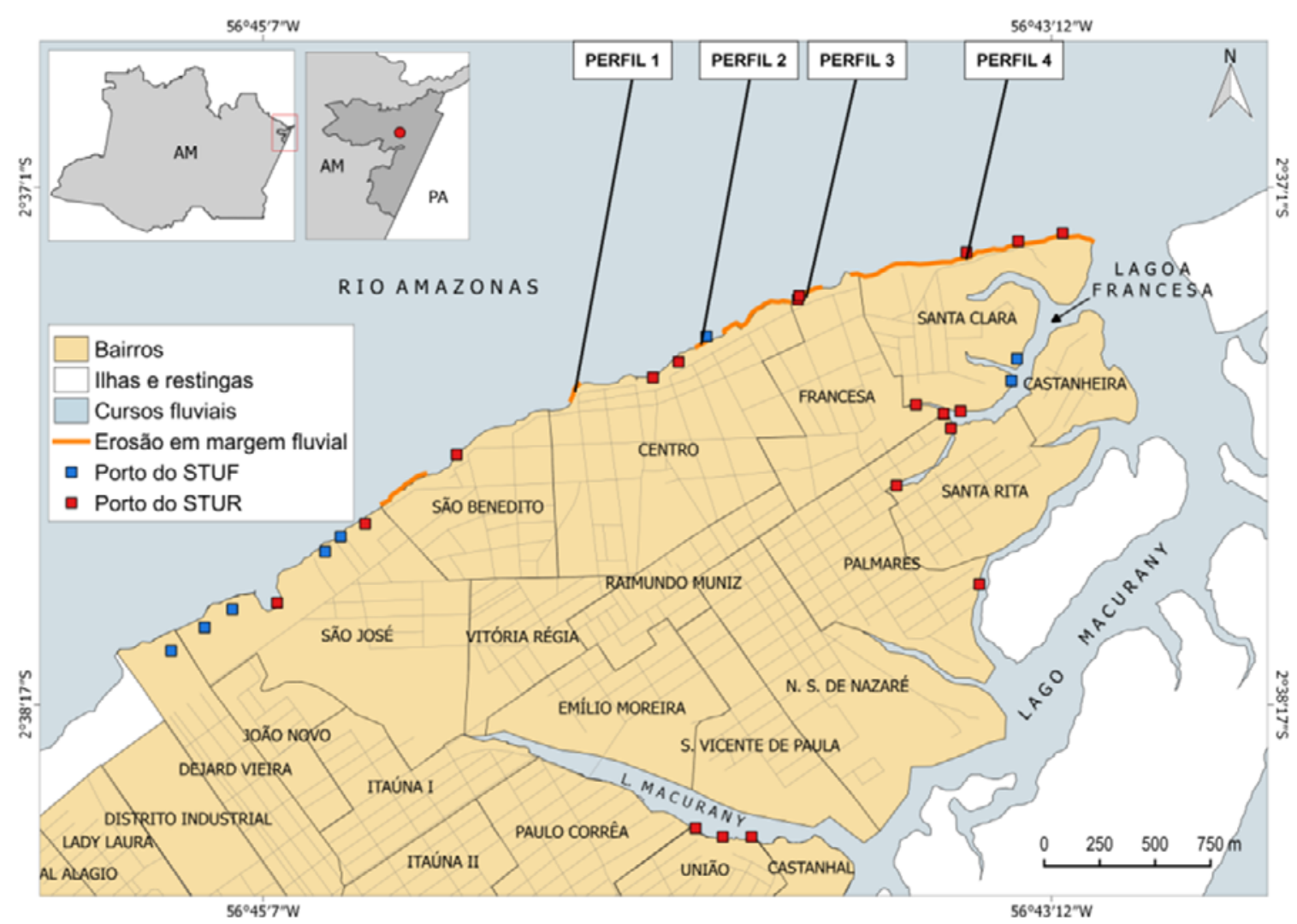

Fonte: Base cartográfica IBGE, 2010. Adaptado de Marques (2017).

6 Deixaremos de lado os cargueiros utilizados para transporte de produtos produzidos pelo Polo Industrial de Manaus e os transatlânticos de turistas que ancoram em Parintins, pois exigiriam ampliação dos sistemas atrelados a outras frações do capital, mas sendo tema de estudos frutíferos em pesquisas futuras.
Devido a sua posição, Parintins é um centro distribuidor de produtos industrializados oriundos tanto de Manaus como da rede urbana paraense. Cidades médias como Parintins possuem especializações comerciais não existentes nas cidades pequenas do seu entorno, como no caso de materiais de construção, em que os 
sete grandes grupos são responsáveis pela distribuição para municípios circunvizinhos e comunidades sob sua área de influência. Tais grupos controlam também a distribuição de outras mercadorias, como gás, estivas e alimentos industrializados. Por possuírem balsas próprias que trazem mercadorias da capital amazonense, contribuem para que ocorra domínio e concentração dos mercados locais, ainda mais nos últimos anos. A maneira com que o STUF se beneficia das redes de sujeitos pertencentes ao Stur para distribuir ou receber produtos denota ao termo territorial seu sentido clássico, associado às relações de poder, pois redes de atores sintagmáticos acabam influenciando a configuração de frações do espaço em beneficio próprio (RAFFESTIN, 1993).

A caracterização em morfologia urbana e seus elementos são fundamentais para esse tipo de análise. Sistematizados por Whitacker e Miyazaki (2012), são apresentados na primeira coluna do Quadro 2, que, associados aos resultados até aqui discutidos, permitem elencar um guia metodológico específico para cidades com dinâmicas ribeirinhas. Aos aspectos relativos ao sítio/plano/paisagem, inserimos as relações destes com os sistemas territoriais (Stur/Stuf).

Quadro 2 - Elementos para estudo de morfologia urbana em cidades de dinâmicas ribeirinhas.

\begin{tabular}{ll}
\hline Elementos/morfologia & \multicolumn{1}{c}{ Geomorfologia e dinâmicas fluviais } \\
\hline O plano urbano e a & - Averiguar como a evolução do plano se \\
evolução do plano & adequa às nuances do relevo, margens fluviais \\
& e aos limites expansivos. \\
& - Descrever a base geológica e geomorfológica \\
& a partir dos relatórios e dados da CPRM \\
& (2013) e da Folha SA.21 - Santarém. \\
& - Verificar se a justaposição do plano se \\
& complementa tecnicamente sobre o relevo e se \\
& respondem as condições sazonais dos rios.
\end{tabular}

\section{Relações do plano} com o sítio urbano
- Considerar a sazonalidade do regime hídrico amazônico.

- Analisar os impactos de planos assentados em sítios constituídos por arquipélagos fluviais, várzeas baixas, terraços etc. - O tipo de relevo que o plano urbano se assenta pode indicar condicionantes ou limitações pela existência de áreas inundáveis e erosão de margens fluviais.

- Verificar a viabilidade dos planos quanto à geometria das formas de fundo fluviais nas proximidades das margens fluviais.

- Considerar as características hidrodinâmicas dos rios (vazão, velocidade e material em suspensão) na execução dos planos que visem áreas de contenção.

- Averiguar se o plano urbano respeita os contornos dos taludes fluviais ou se adequa à rede hidrográfica de igarapés que entrecortam as cidades. 
Quadro 2 - Continuação.

\begin{tabular}{ll}
\hline Elementos/morfologia & \multicolumn{1}{c}{ Geomorfologia e dinâmicas fluviais } \\
\hline Fisionomia urbana & - Considerar, partindo dos elementos naturais \\
& e sociais de forma dialética, elementos que \\
& indiquem constante processo coevolutivo: \\
& descrever construções, embarcações e \\
& margens fluviais. \\
& - Descrever representações sociais e da \\
& natureza presentes na paisagem urbana, \\
& indicando aspectos recursivos utilizados pelas \\
& populações. Ex.: uso da madeira, palha para \\
& moradias e embarcações; descrever tipologias \\
& de habitações populares (hibridismos).
\end{tabular}

Relação entre o que é edificado e o que não é edificado
- Limites de construção de edificações condicionados por relevos de margens fluviais. - Averiguar se afetam mobilidade e acessibilidade.

- Analisar a desvalorização devido às perdas de solo de propriedades pela vulnerabilidade geológica (estrutura vertical dos perfis das margens fluviais) e condições geomorfológicas do relevo (altura e declividade da encosta fluvial).

- Averiguar a possível fragilidade do pacote sedimentar em áreas de circulação de veículos nas margens fluviais.

- Analisar a relação do relevo com tipo de ocupação urbana e problemas socioambientais.

ocupação e
identificação de áreas
morfologicamente
homogêneas e
heterogêneas

- Áreas inundáveis/aglomerados palafíticos.

- Áreas de portos navegáveis o ano todo/ ocupação por setores dominantes.

- Áreas de portos com margem do tipo falésia fluvial/ocupação e adequação por setores da economia popular.

\section{Sistemas territoriais}

- Análise de elementos arquitetônicos, referenciais, contínuos ou fragmentados, representativos do poder estatal ou privado, simbólicos ou banais.

- Evidenciar a fragmentação urbana.

- Indicar permanência de elementos arquitetônicos de ciclos passados

Stuf: elementos modernos associados aos fixos - tipo de arquitetura e amplas áreas apropriadas por grupos dominantes.

Stur: tipos de moradias e uso de recursos regionais, margens de rios com uso coletivo, moradias, portos, rampas e flutuantes populares.

- Indícios podem determinados por condições culturais e ambientais

Stuf: melhor estrutura auxiliando práticas dos grupos. Portos, galpões, postos de gasolina em margens fluviais, flutuantes de ferro.

Stur: menos quantidade de fixos auxiliando práticas espaciais. Portos improvisados, flutuantes com uso de toras de madeira ou garrafas PET, moradias palafíticas.

- Identificação de centralidades por meio dos fixos referenciais:

Stuf: longos trechos valorizados de portos, postos de gasolina em margens fluviais, flutuantes de ferro.

Stur: aglomerações de usos populares citados no item anterior; contínuos conjuntos de habitações vernaculares (aglomerados de palafitas).

Fonte: Adaptado de Whitacker e Miyazaki (2012).

\section{CONSIDERAÇÕES FINAIS}

Um dos desafios da geografia urbana, particularmente estudos sobre a morfologia, está em considerar em sua abordagem as várias escalas e dimensões necessárias para o entendimento da forma da cidade. Por isso, torna-se essencial considerar, junto ao processo de reestruturação econômica regional (e suas variantes que geram êxodo rural e outros processos), a análise conjunta das características físicas em que se assenta o sítio, resultando na proposta metodológica do Quadro 2. Além de evidenciar a importação de formas exógenas na formação do plano urbano, devem ser considerados elementos que compõem a paisagem e dão sentido à forma. Como limites de ocupação do arquipélago parintinense são cada vez mais claros pela dispersão urbana que vem ocorrendo, grandes áreas de ocupação irregulares e diversas formas de apropriação por frações dominantes causam sérios problemas socioambientais.

O regime fluvial, a fisiografia dos rios e a geomorfologia do sítio em cidades com forte dinâmica ribeirinha, necessitam ser entendidos como variáveis que condicionam ou limitam a navegação e atracação de embarcações, o que pode refletir em perdas e ganhos de centralidade e na forma como se dão os usos e disputas pelas margens fluviais e lagos. Com localização privilegiada no rio Amazonas e com a navegabilidade sem restrições durante o ano, Parintins exerce centralidade e dinâmica diferenciadas das demais cidades do baixo Amazonas, caracterizando-se como uma cidade média de responsabilidade territorial (BARTOLI et al., 2019), com papel marcante na rede urbana sub-regional. Associar a discussão do sítio (base física do plano) à situação (relações com a rede, fluxos e centralidade) requer entendimento de 
que as redes locais de sujeitos realizam disputas territoriais pelo controle das margens fluviais, inerentes ao processo de territorialização em que o capital mercantil tem sido preponderante. A erosão torna ainda mais raras as margens fluviais, indicador do acesso e mobilidade reduzidos de classes populares às margens frontais da cidade pela privatização dos portos pertencentes ao Stuf.

Em relação à escala regional, pode-se inferir que os fatores físicos, como no caso do rio, sempre desempenham papel importante na dinâmica da rede urbana, o que pode ser verificado desde as primeiras incursões de exploração na região, à importância para rede de escoamento durante a economia da borracha até às dinâmicas mais recentes, e raramente são considerados nos estudos de tipologias de cidades. Por isso é preciso aprofundar as discussões acerca dos Stur e dos Stuf, as sazonalidades, temporalidades e padrões que podem condicionar a existência de fluxos e dinâmicas diferenciadas nas interpretações observadas em Parintins e no baixo Amazonas.

\section{REFERÊNCIAS}

AGÊNGIA NACIONAL DE ÁGUAS; COMPANHIA DE PESQUISAS E REGURSOS MINERAIS; SISTEMA DE PROTEÇÃO DA AMAZÔNIA. Monitoramento hidrológico. Manaus: CPRM, 2015. (Boletim n 04-30/01/2015).

BARTOLI, E. O retorno ao território a partir da cidade: sistemas territoriais urbano-ribeirinhos em Parintins (AM). 2017. Tese (Doutorado em Geografia) Universidade Estadual Paulista, Presidente Prudente, 2017.

BARTOLI, E. Cidades na Amazônia, sistemas territoriais e a rede urbana. Mercátor, Fortaleza, v. 17, e17027, p. 1-16, 2018a.

BARTOLI, E. Entre o urbano e o ribeirinho: territorialidades navegantes e sistemas territoriais em Parintins (AM). Rio de Janeiro: UFRJ, 2018b.

BARTOLI, E. Territorialidades urbano-ribeirinhas: o sistema territorial pesqueiro de Parintins (AM). Revista GeoNorte, Manaus, v. 10, n. 35, p. 38-56, 2019a.

BARTOLI, E. Tilheiros: carpintaria naval e sistemas territoriais em Parintins-AM. Revista Desenvolvimento Meio Ambiente, Curitiba, v. 51, p. 43-62, 2019b.
BARTOLI, E; SCHOR, T; OLIVEIRA, J. A. Gidades médias na Amazônia: ampliando percepções sobre a responsabilidade territorial de Parintins (AM). Ponta Grossa: UEPG, 2019. Disponível em: https://bit.ly/ 3d5uywy. Acesso em: 19 dez. 2018.

BECKER, B. K. A geopolítica na virada do milênio: logística e desenvolvimento sustentável. In: CASTRO, I. et al. (org.). Geografia: conceitos e temas. Rio de Janeiro: Bertrand Brasil, 2005. p. 271-307.

\section{BITTENCOURT, A. G. R. Memória do município} de Parintins: estudos históricos sobre origem, desenvolvimento moral e material. Manaus: Edições do Governo do Estado do Amazonas, 1924.

CANO, W. Reflexões sobre o papel do capital mercantil na questão regional e urbana do Brasil. Campinas: Instituto de Economia da Unicamp, 2010.

CAPEL, H. La Morfologia de lasciudades. Barcelona: Ediciones del Serbal, 2002.

CARVALHO, J. A. L. Terras caídas e consequências sociais: Costa do Miracauera, Paraná da Trindade, município de Itacoatiara-AM. 2006. Dissertação (Mestrado em Sociedade e Cultura na Amazônia) - Universidade Federal do Amazonas, Manaus, 2006.

GARVALHO, R. A. A expansão urbana de Parintins: produção do espaço, agentes e processos socioespaciais. 2013. Monografia (Graduação em Geografia) - Universidade do Estado do Amazonas, Parintins, 2013.

CASTRO, I. E. Geografia e política: território, escalas de ação e instituições. Rio de Janeiro: Bertrand Brasil, 2005.

GORRÊA, R. L. periodização da rede urbana na Amazônia. In: CORRÊA, R. L. (org.). Estudos sobre a rede urbana. Rio de Janeiro: Bertrand Brasil, 2006. p. 181-253.

COSTA NETO, M. A. Mudanças no uso do solo na cidade de Parintins: o caso da Lagoa da Francesa. 2011. Monografia (Graduação em Geografia) - Universidade do Estado do Amazonas, Parintins, 2011. 
LANDIM, P. C. Desenho de paisagem urbana: as cidades do interior paulista. São Paulo: Unesp, 2004.

MARQUES, R. O. Erosão nas margens do rio Amazonas: o fenômeno das terras caídas e as implicações para a cidade de Parintins - AM. 2017. Dissertação (Mestrado em Geografia) - Universidade Federal do Amazonas, Manaus, 2017.

NASCIMENTO, E. G. Loteamento recente em Parintins/AM (Pascoal Alágio): uma breve consideração e diagnóstico de suas principais características. 2011. Monografia (Graduação em Geografia) - Universidade do Estado do Amazonas, Parintins, 2011.

RAFFESTIN, G. Por uma geografia do poder. São Paulo: Ática, 1993.

ROSAL, E. Uma análise sobre o ciclo da juta no município de Parintins. 2000. Monografia (Graduação em Geografia) - Universidade Federal do Amazonas, Manaus, 2000.

SAUNIER, T. Parintins: memória dos acontecimentos históricos. Manaus: Valer, 2003.

SCHOR, T.; OLIVEIRA, J. A. Parintins: a geografia da saúde na formação da cidade média de responsabilidade territorial. In: BARTOLI, E. et al. (org.). Parintins: sociedade, territórios \& linguagem. Manaus: Edua, 2016. p. 35-58.
SECRETARIA MUNICIPAL DE ASSISTÊNCIA SOCIAL E TRABALHO. Relatório União. Parintins, 2009

SILVA, F. Capital mercantil, transportes fluviais e a rede urbana sub-regional de ParintinsAM. 2018. Monografia (Graduação em Geografia) Universidade do Estado do Amazonas, Parintins, 2018.

SOUZA, N. D. O processo de urbanização de Parintins (AM): evolução e transformação. 2013. Tese (Doutorado em Geografia Humana) - Universidade de São Paulo, São Paulo, 2013.

SPOSITO, M. E. B. O estudo das cidades médias brasileiras: uma proposta metodológica. In: SPOSITO, M. E. B. (org.). Gidades médias: espaços em transição. São Paulo: Expressão Popular, 2007.

TRINDADEJUNIOR, S. G. G. Diferenciação territorial e urbanodiversidade: elementos para pensar uma agenda urbana em nível nacional. Revista Cidades, Presidente Prudente, v. 7, n. 12, p. 227-255, 2010.

WITACKER, A.; MIYAZAKI, V. O estudo das formas urbanas no âmbito da geografia urbana: apontamentos metodológicos. Coimbra: Universidade de Coimbra, 2012. Disponível em: https://bit.ly/2TVekiO. Acesso em: 20 jul. 2019. 